\title{
Determining the Effects of Abscisic Acid Drenches on Evapotranspiration and Leaf Gas Exchange of Tomato
}

\author{
Manuel G. Astacio and Marc W. van Iersel ${ }^{1}$ \\ Department of Horticulture, The University of Georgia, 1111 Miller Plant \\ Sciences Building, Athens, GA 30602
}

Additional index words. photosynthesis, shelf life, stomates, stomatal conductance, transpiration, wilting

\begin{abstract}
It is common for plants in the retail market to receive inadequate water and lose aesthetic value within a short period of time. The plant hormone abscisic acid (ABA) is naturally produced in response to drought conditions and reduces transpiration $(E)$ by closing the stomata. Thus, ABA may lengthen shelf life of retail plants by reducing water loss. Two studies were conducted to look at effects of $A B A$ on plant water use and shelf life over a 13-day period and short-term effects of ABA on leaf physiology. The objective of the short-term study was to determine how quickly $100-\mathrm{mL}$ drenches of $250 \mathrm{mg} \cdot \mathrm{L}^{-1}$ ABA solution affect leaf gas exchange of tomatoes (Solanum lycopersicum 'Supersweet $\left.100^{\prime}\right)$. ABA drenches reduced stomatal conductance $\left(g_{S}\right), E$, and photosynthetic rate $\left(P_{n}\right)$ within 60 min. After $2 \mathrm{~h}, \mathrm{E}, g_{\mathrm{s}}$, and $P_{\mathrm{n}}$ were reduced by $66 \%, 72 \%$, and $55 \%$ respectively, compared with the control plants. In the13-day study, $\mathrm{ABA}$ was applied to tomatoes as a $100-\mathrm{mL}$ drench at concentrations ranging from 0 to $1000 \mathrm{mg} \cdot \mathrm{L}^{-1}$ and $A B A$ effects on water use and time to wilting were quantified. Half of the plants were not watered after ABA application, whereas the other plants were watered as needed. In general, higher ABA concentrations resulted in less water use by both well-watered and unwatered plants. ABA delayed wilting of unwatered plants by 2 to 8 days (dependent on the dose) as compared with control plants. In well-watered plants, $A B A$ reduced daily evapotranspiration (ET) for 5 days, after which there were no further ABA effects. Negative side effects of the $A B A$ application were rate-dependent chlorosis of the lower leaves followed by leaf abscission. These studies demonstrate that ABA drenches rapidly close stomata, limit transpirational water loss, and can extend the shelf life of retail plants by up to 8 days, which exemplifies its potential as a commercially applied plant growth regulator.
\end{abstract}

Inadequate watering during retail diminishes the salability and shelf life of plants (Armitage, 1983), resulting in economic losses for growers and/or retailers. One way to reduce water use and extend the shelf life of plants in retail settings is by the application of exogenous ABA (Barrett and Campbell, 2006), although the duration of the effects is dependent on species, application rate, and application method (Blanchard et al., 2007; Kim and van Iersel, 2011; Sharma et al., 2006; van Iersel et al., 2009; Waterland et al., 2010a, 2010b). The effects of ABA can be profound and have commercial implications. Until recently, use of ABA was cost-prohibitive for horticultural applications and relegated to research. However, breakthroughs in microbiology have made it possible to produce ABA at much lower costs (Petracek et al., 2005) and Valent BioSciences registered $\mathrm{ABA}$ as a plant growth regulator for use on ornamental plants with the

Received for publication 5 Aug. 2011. Accepted for publication 9 Sept. 2011.

We thank Valent BioSciences Corp. for their financial support and Fafard, Inc. for donation of the substrate. We also thank Lisa Donovan, Hazel Wetzstein, and three anonymous reviewers for their constructive comments.

${ }^{1}$ To whom reprint requests should be addressed; e-mailmvanier@uga.edu.
U.S. Environmental Protection Agency in 2010 (Runkle, 2009). As such, there is potential for the use of $\mathrm{ABA}$ as a plant growth regulator in commercial horticulture, although there are still questions of possible phytotoxic responses and deleterious long-term effects (Abrams et al., 1997; Kim and van Iersel, 2011; Waterland et al., 2010b), including flower abscission (Barrett and Bartuska, 2011). ABA has also been shown to result in increased leaf temperatures and leaf burn, especially under high light conditions (O'Donoughue et al., 2011), presumably because ABA applications reduce the evaporative cooling that results from transpiration.

ABA was first identified in the mid-1960s (Ohkuma et al., 1965) and has since been shown to affect a myriad of plant processes, including acclimation to cold and drought stress (Bravo et al., 1998; Wilen et al., 1994). Studies have also examined the effect of artificially high levels of ABA on leaf physiology. Plants grown under high $\mathrm{ABA}$ conditions exhibit smaller stomates in higher density than control plants (Franks and Farquhar, 2001). One of the most scrutinized ABA effects is that on $g_{\mathrm{S}}$. $\mathrm{ABA}$ is produced in response to drought conditions, accumulating in the leaves and causing the guard cells to respond by either closing stomata or preventing them from opening (Jiang and Hartung, 2008; Tallman, 2004; Willmer and
Fricker, 1996), thus reducing transpiration (Mahdieh and Mostajeran, 2009; Milborrow, 1974). Specifically, when a plant is exposed to decreased soil moisture, tissues in the root tips, cortex, and stele begin to synthesize ABA. From there, the ABA is translocated through the xylem to the leaves (Hartung et al., 2002). The guard cells take up the ABA quickly, within $30 \mathrm{~min}$ in some cases (Walton, 1980). Once inside the guard cells, ABA regulates movement of ions and solutes such as $\mathrm{H}^{+}, \mathrm{K}^{+}$, $\mathrm{Cl}^{-}$, and malate, in and out of the stomates, causing the guard cells to lose turgor and the stomata to close (Walton, 1980). These findings support the idea that ABA produced in the roots is the primary hormone responsible for closing stomata and preventing water loss, resulting in plant acclimation to drought conditions (Davies et al., 1987). However, not all ABA is produced in the roots, because Christmann et al. (2007) showed that arabidopsis (Arabidopsis thaliana) leaves are capable of de novo synthesis of ABA. Once leaves are rehydrated, ABA is rapidly catabolized and concentrations decrease to pre-stress levels (Zeevaart and Creelman, 1988).

The potential of ABA to extend the retail shelf life of bedding plants has recently been examined with encouraging results. When ABA $\left(250 \mathrm{mg} \cdot \mathrm{L}^{-1}\right)$ is applied as a sprench (spraying the leaves and allowing the excess solution to moisten the substrate), the shelf life of 'New Guinea' impatiens (Impatiens hawkeri) is prolonged by almost $6 \mathrm{~d}$, although the same rate extends the shelf life of verbena (Verbena $\times$ hydrida) by only $1 \mathrm{~d}$ (Blanchard et al., 2007). Other studies have found that drench applications of ABA increase the shelf life of hydrangea (Hydrangea macrophylla) by up to $11 \mathrm{~d}$ (van Iersel et al., 2009) and of salvia (Salvia splendens) by up to $5 \mathrm{~d}$ (Kim and van Iersel, 2011), depending on the rate. Work on six different annual bedding plants found that a $500-\mathrm{mg} \cdot \mathrm{L}^{-1}$ ABA drench increases shelf life of marigold (Tagetes patula) by $3 \mathrm{~d}$ and is more effective than a foliar spray of the same rate. On the other hand, pansy $($ Viola $\times$ wittrockiana) responds better to a spray than a drench application, demonstrating that application method is as important of a consideration as rate (Waterland et al., 2010a). However, there are still questions about exogenous ABA on plant water use such as its effects on ET and how quickly it affects leaf gas exchange. In addition, the plants in the studies mentioned previously were all subjected to drought stress. Little work has been done comparing the effects of ABA on wellwatered plants.

We conducted two studies to quantify the effects of ABA drenches on tomato. Tomatoes were used as the model crop because they are responsive to ABA applications (Sharma et al., 2006). The objectives of the first study were to evaluate the effects of exogenous ABA on the ET of drought-stressed and well-watered tomatoes and to quantify how ABA affects the time to wilting. The objectives of the second study were to examine the short-term effects of $\mathrm{ABA}$ drenches on $g_{\mathrm{S}}, \mathrm{E}$, and $\mathrm{P}_{\mathrm{n}}$ of tomato. 


\section{Materials and Methods}

Evapotranspiration and shelf life. Tomatoes 'Supersweet 100' were seeded in 72-cell trays and grown on an ebb and flow bench providing a nutrient solution containing 100 $\mathrm{mg} \cdot \mathrm{L}^{-1}$ nitrogen (15-5-15 Cal-Mag; Scotts, Marysville, $\mathrm{OH} ; 15 \mathrm{~N}-2.2 \mathrm{P}-12.45 \mathrm{~K})$ for $20 \mathrm{~d}$. Seedlings were transplanted on 10 Sept. 2009 into $10-\mathrm{cm}$ round pots filled with soilless substrate (Fafard 2P; Conrad Fafard Inc., Agawam, $\mathrm{MA}$ ) and grown on the load cell system (see subsequently) in a glass greenhouse at the University of Georgia in Athens, GA. The tomatoes were fertilized with $2.6 \mathrm{~g} /$ plant of controlled-release fertilizer (Osmocote14-1414 , Scotts; $14 \mathrm{~N}-6.16 \mathrm{P}-11.62 \mathrm{~K}$ ) as a top dressing and watered by hand daily. A data logger (CR10; Campbell Scientific Inc., Logan, UT) recorded environmental conditions using a quantum sensor (QSO-sun; Apogee Instruments, Logan, UT) and a temperature and humidity sensor (HMP50; Vaisala, San Jose, CA). Daily minimum and maximum temperatures were $18.9 \pm 2.7$ and $26.0 \pm 5.2{ }^{\circ} \mathrm{C}$, minimum and maximum vapor pressure deficit were $0.168 \pm$ 0.09 and $0.953 \pm 0.858 \mathrm{kPa}$, and daily light integral was $11.8 \pm 4.3 \mathrm{~mol} \cdot \mathrm{m}^{-2} \cdot \mathrm{d}^{-1}$ (mean \pm $\mathrm{SD})$ in the period before the ABA treatments.

ABA stock solution $(10 \% \mathrm{w} / \mathrm{v}$ s-ABA, the biologically active form of ABA, VBC-30101; Valent BioSciences, Libertyville, IL) was diluted with deionized water to yield concentrations of $0,62.5,125,250,500$, and 1000 $\mathrm{mg} \cdot \mathrm{L}^{-1}$. This range of concentrations was chosen based on prior research that showed high efficacy at concentrations of 250 to 2000 $\mathrm{mg} \cdot \mathrm{L}^{-1}$, although concentrations higher than $1000 \mathrm{mg} \cdot \mathrm{L}^{-1}$ resulted in significant leaf abscission in annual salvia (Salvia splendens) (Kim and van Iersel, 2011). ABA applications were made on 13 Oct. $2009, \approx 1$ month after transplanting. The tomatoes were watered to runoff the prior evening to assure that all pots were at container capacity, and each pot was drenched the next afternoon with $100 \mathrm{~mL}$ of ABA solution applied to the substrate surface. After the ABA applications, water was withheld from half of the plants (unwatered), whereas the other half was watered as needed (well-watered) based on visual appearance of the substrate and measured ET.

Visual observations of wilting, chlorosis, and lower leaf abscission were taken daily for the duration of the study, but these symptoms were not quantified. In addition, pot weight was measured with individually calibrated 1and 2-kg load cells (LSP-1 and LSP-2; Transducer Techniques, Temecula, CA) mounted on level sections of a metal frame and connected to a multiplexer (AM416; Campbell Scientific Inc.) and data logger (CR10; Campbell Scientific). Weight measurements were taken every $10 \mathrm{~s}$, and these measurements were averaged and recorded every $10 \mathrm{~min}$. Cumulative weight loss over the course of the study was calculated as a measure of cumulative ET. For wellwatered plants, data were corrected for the amount of water applied at each irrigation. Daily ET was determined as the change in pot weight in $24 \mathrm{~h}$ after correcting for irrigation when needed. Environmental conditions during the measurement period are summarized in Figure 1.

The experiment was designed as a randomized complete block with a split plot with $\mathrm{ABA}$ concentrations as the main blocking factor and the well-watered/unwatered factor as the split. There were two blocks and the experimental unit was an individual plant. A total of 24 plants were used (six ABA concentrations $\times$ two irrigation regimes $\times$ two blocks). ABA effects were analyzed separately for the well-watered versus the unwatered treatments using regression analysis. Because hormonal effects on plant physiology are generally not directly proportional to the hormonal concentration, ABA concentrations were transformed using $\log ([\mathrm{ABA}]+50)$ before testing for linear and quadratic effects of ABA on ET. The data were analyzed separately for each day. Time to wilting of unwatered plants was also analyzed using regression.

Short-term gas exchange responses. 'Supersweet 100' tomatoes were seeded in 72-cell trays in a glass greenhouse. After germination, seedlings were grown to size on an ebb and flow bench providing a $100 \mathrm{mg} \cdot \mathrm{L}^{-1}$ nitrogen fertilizer solution (15-5-15 Cal-Mag, Scotts; $15 \mathrm{~N}-2.2 \mathrm{P}-12.45 \mathrm{~K})$. The seedlings were transplanted into $10-\mathrm{cm}$ round pots filled with soilless substrate (Fafard 1P; Conrad Fafard Inc.) on 21 Jan. 2011 and grown under an overhead irrigation system for $16 \mathrm{~d}$. Each plant received $2.6 \mathrm{~g} / \mathrm{plant}$ of controlled-release fertilizer (Osmocote 14-14-14, Scotts; 14N$6.16 \mathrm{P}-11.62 \mathrm{~K})$.

The plants were then transferred to two growth chambers (E-15; Conviron, Winnipeg, Manitoba, Canada) on 6 Feb. 2011 and given a minimum of $2 \mathrm{~d}$ to acclimate to the conditions within. The growth chambers were set to $12 \mathrm{~h}$ days at $25^{\circ} \mathrm{C}$ with a photosynthetic photon flux of $515 \mu \mathrm{mol} \cdot \mathrm{m}^{-2} \cdot \mathrm{s}^{-1}$ and $12-\mathrm{h}$ nights at $21^{\circ} \mathrm{C}$. While in the growth chamber, plants were watered by hand daily until the start of data collection.

To collect gas exchange data, the cuvette of a portable leaf photosynthesis system (Ciras-2; PP Systems, Amesbury, MA) was clamped onto the uppermost, fully expanded leaf of a plant before treatment and leaf gas exchange was recorded every $5 \mathrm{~min}$. Once stable readings were achieved and pretreatment data were gathered for $30 \mathrm{~min}$, treatments were applied and leaf gas exchange data were collected for $\approx 3 \mathrm{~h}$. Plants were drenched with 100 $\mathrm{mL}$ of deionized water or $250 \mathrm{mg} \cdot \mathrm{L}^{-1} \mathrm{ABA}$ solution made from ABA stock solution (VBC30101; Valent BioSciences). This concentration was chosen based on the results from the ET and shelf life study to minimize the risk of negative side effects of the ABA while being effective in reducing ET.

Two plants (one ABA treatment and one control) were measured per day over the course of $11 \mathrm{~d}$ ( 8 Feb. through 18 Feb. 2011). A total of five replications (two treatments $\times$ five replications) were used, although stable readings were not achieved for one ABA-treated plant, resulting in only four usable replications for this treatment. To determine instantaneous

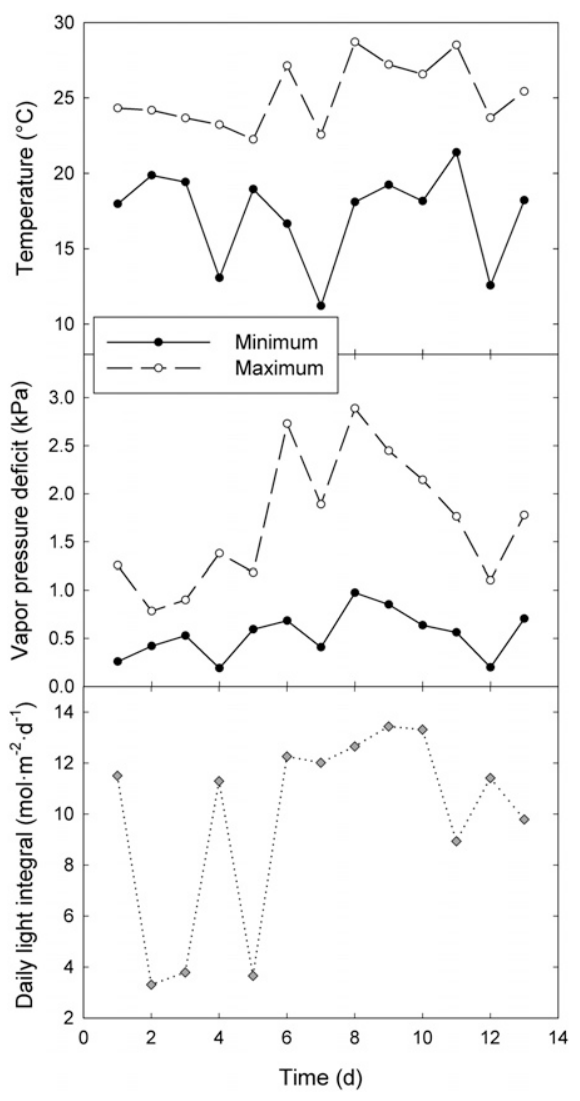

Fig. 1. Environmental conditions inside the greenhouse for the $13 \mathrm{~d}$ duration of the evapotranspiration study. Minimum and maximum daily values for temperature and vapor pressure deficit are given as well as the daily light integral. ABA applications were made on Day 1. $\mathrm{ABA}=$ abscisic acid.

water use efficiency (WUE), $\mathrm{P}_{\mathrm{n}}$ was divided by $\mathrm{E}$. Leaf gas exchange data were normalized by expressing them as a percentage of the pretreatment rate and analyzed by analysis of variance (SAS 9.2; SAS Institute, Cary, NC).

\section{Results and Discussion}

Evapotranspiration and shelf life. Cumulative ET increased over time in a stepwise manner, because the plants used more water during the day then at night, when the stomata are closed and the vapor pressure deficit is smaller (Fig. 2). ABA-treated plants had lower ET than control plants, indicating that ABA caused stomatal closure, limiting transpirational water loss. A reduction in the cumulative ET of the unwatered, ABA-treated plants was apparent within $1.5 \mathrm{~h}(P=0.007)$ and similar differences were seen in the wellwatered plants starting $4.5 \mathrm{~h}$ after ABA application $(P=0.03$; Fig. 2$)$. ABA effects on cumulative ET remained significant throughout the remainder of the study, both in the unwatered and well-watered treatments $(P<$ $0.001)$. By the end of the second day after ABA application, unwatered control plants had used $82 \mathrm{~mL}$ of water, plants treated with $62.5 \mathrm{mg} \cdot \mathrm{L}^{-1}$ ABA had used $66 \mathrm{~mL}$, and plants treated with 125 to $1000 \mathrm{mg} \cdot \mathrm{L}^{-1} \mathrm{ABA}$ had used only 49 to 


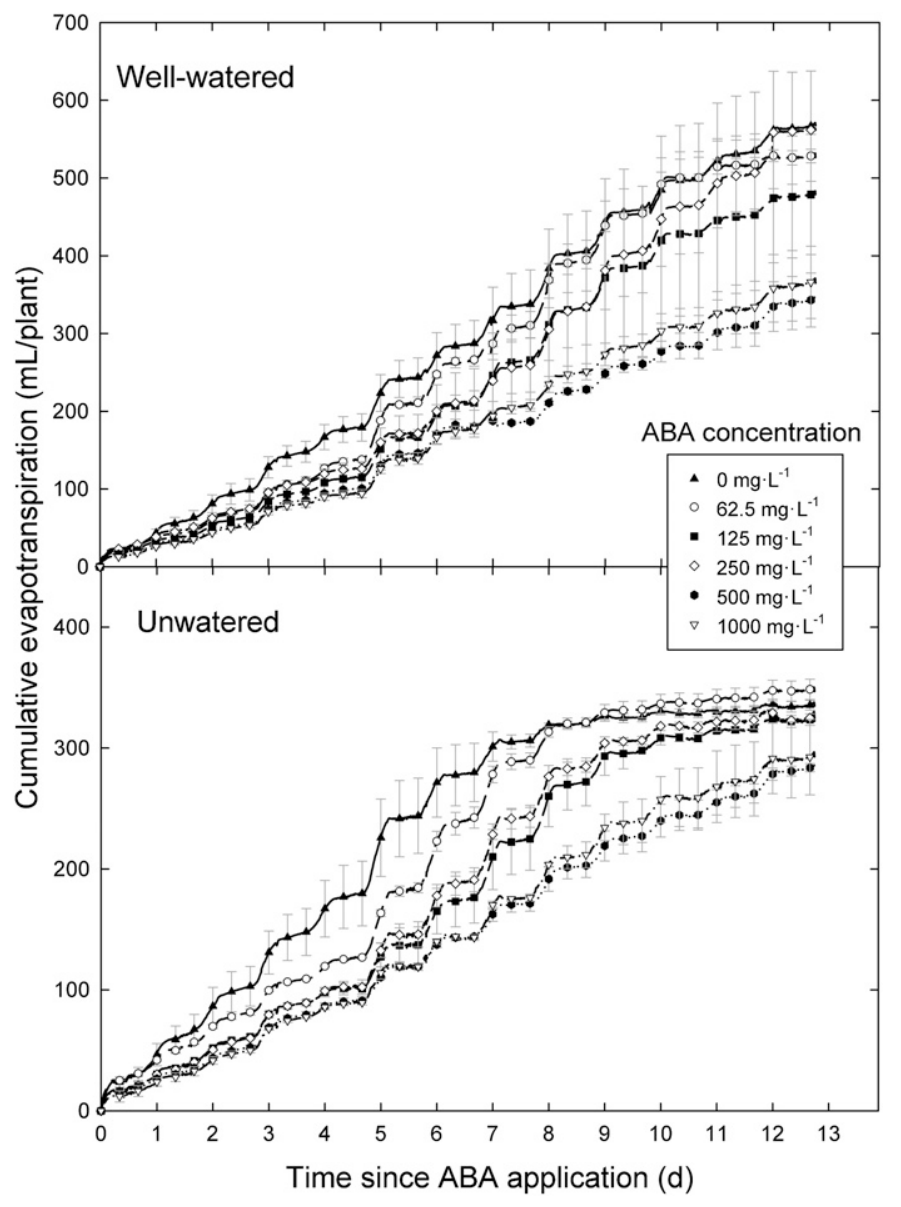

Fig. 2. Cumulative evapotranspiration of tomato during a $13 \mathrm{~d}$ period as affected by $100-\mathrm{mL}$ drenches with different concentrations of ABA. Plants were either well-watered (top) or unwatered (bottom) after ABA application and changes in weight were recorded using load cells connected to a data logger. Significant effects of ABA drenches on cumulative ET were first noted $4.5 \mathrm{~h}$ after ABA application in the well-watered plants $(P<0.03)$ and $1.5 \mathrm{~h}$ after ABA application in the unwatered plants $(P<0.007)$ and persisted throughout the remainder of the study. Data represent the mean $\pm \mathrm{SE}(\mathrm{n}=2) . \mathrm{ABA}=$ abscisic acid; ET = evapotranspiration.

$41 \mathrm{~mL}$ (Fig. 2, bottom). By Day 8, the control plants had used most of the available water $(301 \mathrm{~mL})$ and were wilting, whereas the ABAtreated plants were still transpiring as a result of remaining water availability in the substrate (Fig. 3), causing the differences in cumulative ET to decrease during the last week of the study (Fig. 2). Compared with the unwatered plants, cumulative ET after $13 \mathrm{~d}$ was much higher in the well-watered control plants $(567 \mathrm{~mL})$ than in the unwatered controls ( $335 \mathrm{~mL}, 41 \%$ less) (Fig. 2). Differences in cumulative ET between unwatered and well-watered plants were smaller for ABA-treated plants, e.g., $365 \mathrm{~mL}$ versus $293 \mathrm{~mL}$ (20\% less) for the well-watered and unwatered plants treated with $1000 \mathrm{mg} \cdot \mathrm{L}^{-1}$ (Fig. 2).

The reduced water use of the ABA-treated plants shows that ABA effectively closed stomata, limiting E. This is consistent with previous reports (Jiang and Hartung, 2008; Kim and van Iersel, 2011; Walton, 1980; Waterland et al., 2010c), which indicated that ABA limits $g_{\mathrm{S}}$. Walton (1980) reported that ABA levels in leaves were inversely related to stomatal aperture but concluded that ABA levels alone are not a great indicator of $g_{\mathrm{S}}$, because only a portion of $\mathrm{ABA}$ in the leaves is involved with regulating stomata (Walton, 1980). We found that $\mathrm{ABA}$ drenches reduced water use quickly (within $1.5 \mathrm{~h}$ ) and there was a clear relationship between the ABA concentration of the drench solution and cumulative ET for both the unwatered and well-watered treatments, suggesting that $\mathrm{ABA}$ levels are correlated with stomatal closure. This inverse relationship between cumulative ET and ABA concentration was to be expected, because ABA is largely responsible for limiting $g_{\mathrm{S}}$ by controlling ion flux in and out of guard cells (Walton, 1980) and Kim (2011) showed that there was a strong relationship between leaf ABA concentrations and $g_{\mathrm{S}}$ of petunia (Petunia $\times$ hybrida). Because we applied ABA as a drench, these results also indirectly corroborate the conclusions of Jiang and Hartung (2008) that ABA is transported from the roots through the xylem to the leaf tissue and we have since found that ABA drenches increase leaf ABA concentrations of tomato in a dose-dependent manner (Astacio and van Iersel, 2012).

The ABA concentration also affected daily ET with the unwatered control plants using $35 \mathrm{~mL}$ on the first full day after ABA application, plants in the $62.5 \mathrm{mg} \cdot \mathrm{L}^{-1} \mathrm{ABA}$ treatment using only $25 \mathrm{~mL}$, and higher ABA concentrations reducing daily ET even more, to 15 to $18 \mathrm{~mL}$ (Fig. 3, bottom). On Day 3, the daily ET of the unwatered control plants was $45 \mathrm{~mL}$, whereas the ABA-treated plants used 27 to $28 \mathrm{~mL}$. Unwatered control plants had higher daily ET than unwatered, ABA-treated plants during the first $5 \mathrm{~d}$, but on Day 6 , daily ET of the unwatered control plants dropped sharply and the plants started to wilt. Daily ET started to decrease on Day 7 in the unwatered $62.5 \mathrm{mg} \cdot \mathrm{L}^{-1}$ ABA treatment and on Day 8 for the unwatered 125 and $250 \mathrm{mg} \cdot \mathrm{L}^{-1} \mathrm{ABA}$ treatments (Fig. 3, bottom), indicating the onset of drought stress. From Day 9 to 12, daily ET was highest with the highest ABA concentrations (500 to $1000 \mathrm{mg} \cdot \mathrm{L}^{-1} \mathrm{ABA}$ ), presumably because these treatments had the most water left. These findings are similar to those reported by Kim and van Iersel (2011), who found that $\mathrm{ABA}$ drenches slowed water loss from the substrate with the substrate volumetric water content of the control treatments dropping to $0.1 \mathrm{~m}^{3} \cdot \mathrm{m}^{-3}$ after $2 \mathrm{~d}$, whereas the 1000 and $2000-\mathrm{mg} \cdot \mathrm{L}^{-1}$ plants reached $0.1 \mathrm{~m}^{3} \cdot \mathrm{m}^{-3}$ after 8 and $9 \mathrm{~d}$, respectively. In addition, van Iersel et al. (2009) reported that hydrangeas not treated with ABA used $50 \%$ of the available water within $7 \mathrm{~d}$, whereas the substrate of plants treated with 500 and $1000 \mathrm{mg} \cdot \mathrm{L}^{-1}$ ABA still had $80 \%$ and greater than $90 \%$ of the plant available water left, respectively, at this time. Waterland et al. (2010c) showed that ABA drenches reduced $g_{\mathrm{S}}$ of drought-stressed chrysanthemum (Chrysanthemum $\times$ morifolium) at $1 \mathrm{~d}$ after the $\mathrm{ABA}$ drench, but $g_{\mathrm{S}}$ was very low (less than $50 \mathrm{mmol} \cdot \mathrm{m}^{-2} \cdot \mathrm{s}^{-1}$ ) in both control and ABA-treated plants after $3 \mathrm{~d}$. The effect of $\mathrm{ABA}$ on $g_{\mathrm{S}}$ presumably disappeared after $3 \mathrm{~d}$ because control plants had used most of the available water in the substrate, thus inducing drought stress and stomatal closure, whereas ABA-treated plants had low $g_{\mathrm{S}}$ as a result of the ABA application. The exact duration of ABAinduced reductions in ET is likely to depend on species, ABA concentration and application method, plant water use (e.g., plant size, environmental conditions), and the amount of water available in the substrate at the time of ABA application (e.g., container size, substrate properties).

In the well-watered treatments, ABA reduced daily ET in a dose-dependent manner through Day 5, consistent with the report by Petracek et al. (2005). Water use was similar in all treatments after Day 5, suggesting that the ABA might have lost its effectiveness. Likewise, Waterland et al. (2010c) found that $g_{\mathrm{S}}$ of well-watered chrysanthemum was reduced at 1 and $3 \mathrm{~d}$ after ABA drenches but that $g_{\mathrm{S}}$ of ABA-treated plants was similar to that of control plants at $9 \mathrm{~d}$ after ABA application. This is likely the result of exogenous ABA in the plants being catabolized. The half-life of ABA in tomato was reported to be only $7 \mathrm{~h}$ (Zeevaart and Creelman, 1988). This rapid catabolism of ABA helps explain the importance of ABA dose on the longevity of the response. Treating plants with greater doses of $\mathrm{ABA}$ results in higher leaf tissue concentrations of 
ABA (Astacio and van Iersel, 2012) and it would therefore take longer for enough ABA to be catabolyzed for concentrations to drop to levels where they no longer reduce $g_{\mathrm{S}}$.

Generally, ABA drenches delayed wilting in unwatered plants longer as ABA concentration increased $(P<0.0001)$. Control plants wilted after 6 to $7 \mathrm{~d}$, whereas the plants treated with $62.5 \mathrm{mg} \cdot \mathrm{L}^{-1}$ ABA wilted after $9 \mathrm{~d}$ and plants treated with 500 and $1000 \mathrm{mg} \cdot \mathrm{L}^{-1} \mathrm{ABA}$ after 13 to $15 \mathrm{~d}$ (Fig. 4). The time to wilting was prolonged by overcast weather on Days 2, 3, and 5 , shortly after the ABA applications (Fig. 1). Wilting was only noted in the unwatered

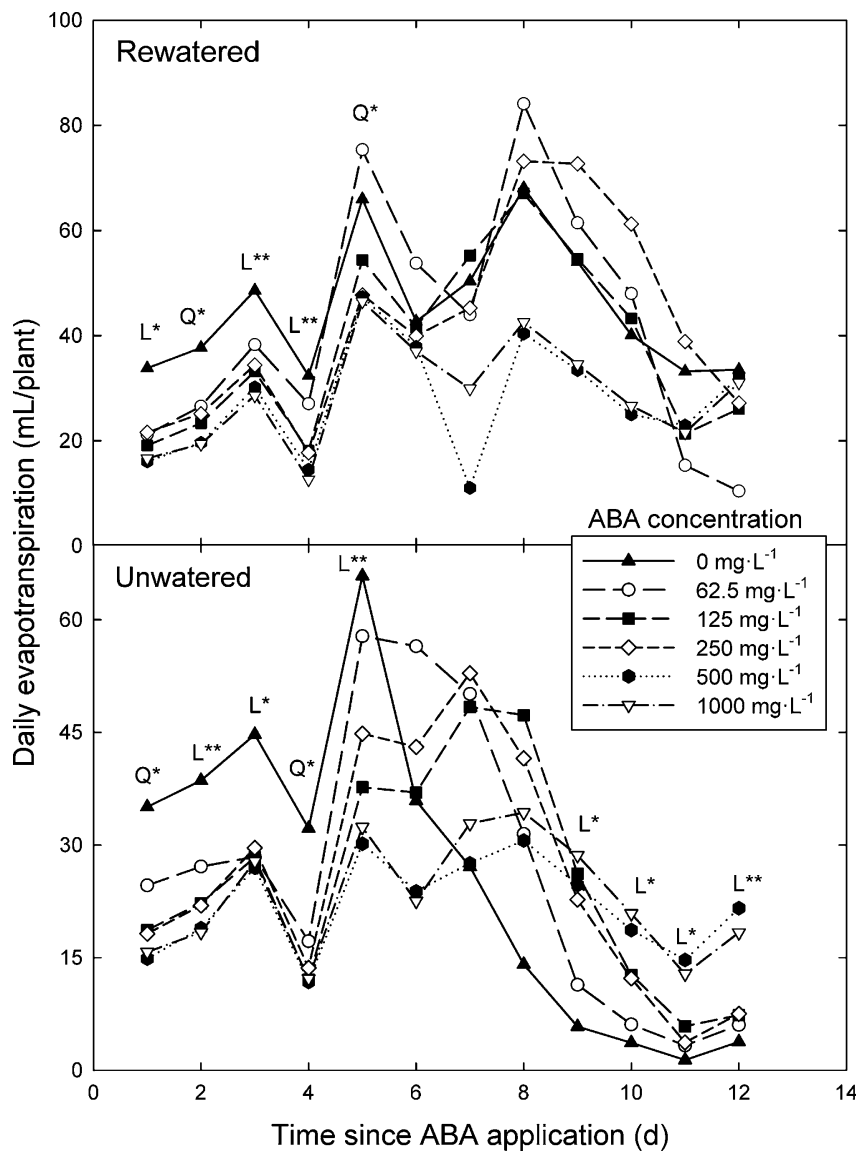

Fig. 3. Daily evapotranspiration of tomato during a 13-d period as affected by drenches with solutions with different concentrations of ABA. Plants were either well-watered (top) or unwatered (bottom) after ABA application. Significant effects of ABA were first noted $1 \mathrm{~d}$ after ABA application $\left({ }^{*} P<0.05\right.$; $\left.{ }^{* *} P<0.01\right) ; \mathrm{L}=$ linear, $\mathrm{Q}=$ quadratic effects of $\log ([\mathrm{ABA}]+50) . \mathrm{ABA}=$ abscisic acid.

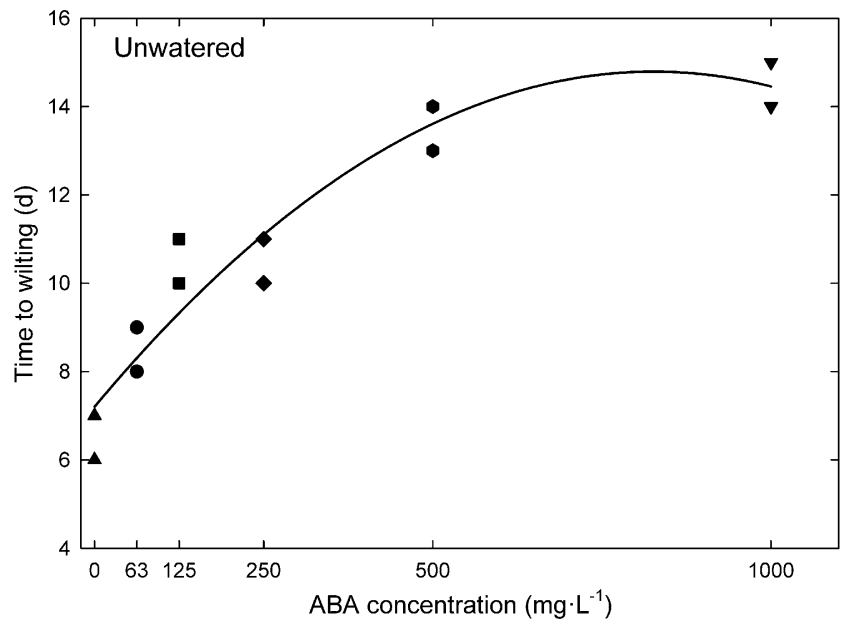

Fig. 4. The effect of drenches with ABA solutions of different concentrations on time to wilting of tomato plants $\left(R^{2}=0.90 ; P<0.0001\right)$. Plants were not well-watered after the initial $\mathrm{ABA}$ applications. $\mathrm{ABA}=$ abscisic acid.

plants; well-watered plants did not wilt. Similar results of shelf life extension were also described for salvia and hydrangea after ABA applications (Kim and van Iersel, 2011; van Iersel et al., 2009) as well as a variety of bedding plants (Blanchard et al., 2007; Sharma et al., 2006; Waterland et al., 2010a, 2010c). These and other studies have found that exogenous ABA can extend the shelf life of common bedding plants from $1 \mathrm{~d}$ in the case of verbena (Blanchard et al., 2007), $4 \mathrm{~d}$ for chrysanthemum (Waterland et al., 2010c), $4.3 \mathrm{~d}$ for petunia (Waterland et al., 2010a), and up to $11 \mathrm{~d}$ for hydrangea (van Iersel et al., 2009). In addition, van Iersel et al. (2009) reported that ABA drenches reduced $g_{\mathrm{S}}$ of unwatered hydrangea for $9 \mathrm{~d}$. We found similar results with tomato, in particular with the well-watered plants in which ABA reduced daily ET for $5 \mathrm{~d}$, after which ABA lost its efficacy (Fig. 3, top).

Foliar chlorosis and leaf abscission were negative side effects of the ABA treatments (results not shown). Chlorosis of lower leaves of plants treated with 250 to $1000 \mathrm{mg} \cdot \mathrm{L}^{-1}$ was first noted $2 \mathrm{~d}$ after ABA applications, and leaf abscission occurred after 4 or $5 \mathrm{~d}$, after which abscission tapered off. Chlorosis has been frequently mentioned as a side effect of high doses of ABA (Blanchard et al., 2007; Kim and van Iersel, 2011; van Iersel et al., 2009; Waterland et al., 2010b). Symptoms were more severe with higher ABA concentrations, which was also reported when salvia (Kim and van Iersel, 2011), hydrangea (van Iersel et al., 2009), or pansy (Waterland et al., 2010b) was treated with high levels of exogenous ABA. Because leaf abscission reduces leaf area, this may further reduce plant water use and delay wilting in addition to the direct effects of $\mathrm{ABA}$ on $g_{\mathrm{S}}$.

Short-term gas exchange responses. ABA drenches quickly and effectively closed stomata and limited transpirational water loss. Significant reductions in $\mathrm{E}, g_{\mathrm{S}}$, and $\mathrm{P}_{\mathrm{n}}$ were seen 55 to 60 min after ABA application $(P<0.05$; Fig. 5). After $2 \mathrm{~h}, \mathrm{ABA}$ reduced $\mathrm{E}, g_{\mathrm{S}}$, and $\mathrm{P}_{\mathrm{n}}$ by $66 \%, 72 \%$, and $55 \%$ respectively, compared with the control plants (Fig. 5). These reductions continued until the end of the 3-h study, when $\mathrm{ABA}$ reduced $\mathrm{E}, g_{\mathrm{S}}$, and $\mathrm{P}_{\mathrm{n}}$ by $71 \%$, $77 \%$, and $61 \%$, respectively, compared with control plants (Fig. 5). A rapid physiological response to $\mathrm{ABA}$ is consistent with the findings that ABA drenches ( 250 to $2000 \mathrm{mg} \cdot \mathrm{L}^{-1}$ ) reduced $g_{\mathrm{S}}$ and $\mathrm{E}$ of salvia within $3 \mathrm{~h}$ (Kim and van Iersel, 2011) and that $g_{\mathrm{S}}$ of hydrangea was negatively correlated with $\mathrm{ABA}$ concentration within $1 \mathrm{~d}$ after treatment (van Iersel et al., 2009). Boldt (2008) used split-root systems to determine how the duration of root exposure to ABA affected $g_{\mathrm{S}}$ of well-watered chrysanthemum and found that an exposure as short as $7.5 \mathrm{~min}$ was enough to induce stomatal closure within $4 \mathrm{~h}$. Walton (1980) reported that there was a $50 \%$ increase in $\mathrm{ABA}$ within the stomata within 30 min after water stress was initiated, indicating that endogenous ABA levels can fluctuate quickly in response to stress.

ABA tended to increase WUE with the ABA-treated plants having a $28 \%$ higher WUE than control plants, although the difference 


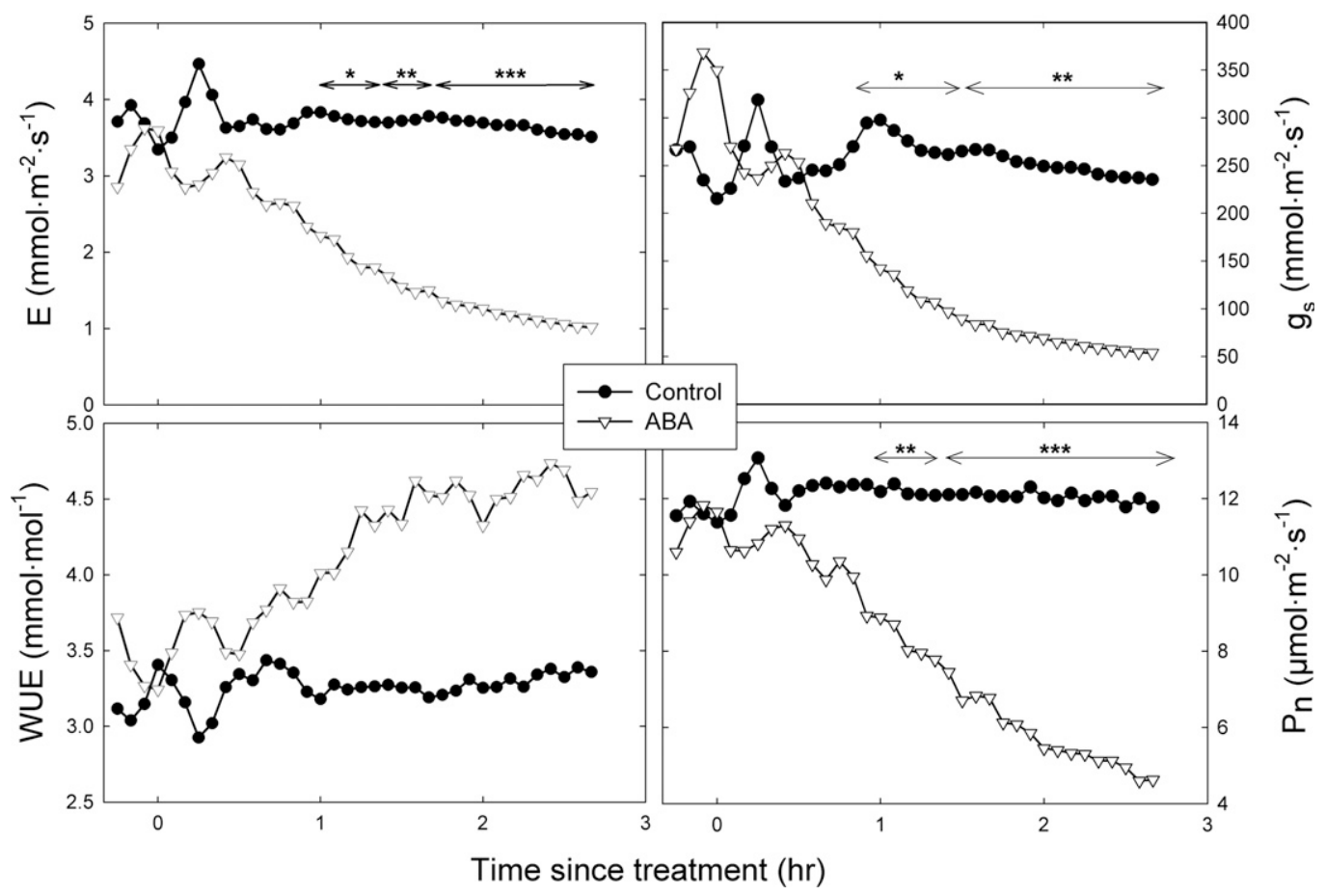

Fig. 5. Transpiration (E), stomatal conductance $\left(g_{\mathrm{S}}\right)$, water use efficiency (WUE), and net photosynthesis $\left(\mathrm{P}_{\mathrm{n}}\right)$ of tomatoes drenched with $100 \mathrm{~mL}$ of either deionized water (control, $\mathrm{n}=5$ ) or $250 \mathrm{mg} \cdot \mathrm{L}^{-1}$ ABA solution $(\mathrm{n}=4)\left({ }^{*} P<0.05 ; * * P<0.01 ; * * * P<0.001\right.$, no significant effects on WUE). Plants were treated at time " $0 . " \mathrm{ABA}=$ abscisic acid.

was never significant ( $P \geq 0.086$; Fig. 5). However, the data suggest that ABA-induced stomatal closure increases WUE. This concept has found practical applications in horticulture. For example, plants can be stimulated to produce ABA by implementing partial root zone drying, which involves exposing part of the root system to dry soil. The resulting increase in endogenous ABA induces stomatal closure and increases WUE (Davies et al., 2002). This raises the question of whether WUE can be increased using exogenous ABA applications as well.

The effect of the ABA applications on E and $g_{\mathrm{S}}$ is consistent with previous reports that ABA is largely responsible for controlling $g_{\mathrm{S}}$, which in turn greatly affects $\mathrm{E}$ (Kim and van Iersel, 2011; Walton, 1980) and photosynthesis (Franks and Farquhar, 2001; Liang et al., 1997). Reductions in $g_{s}$ resulting from drought stress can in turn lead to reduced $\mathrm{P}_{\mathrm{n}}$ (Farquhar and Sharkey, 1982). Liang et al. (1997) reported that drought stress-induced ABA increases led to the reduction of both $g_{\mathrm{S}}$ and $\mathrm{P}_{\mathrm{n}}$ of two tropical tree species over a period of $4 \mathrm{~d}$ and that recovery to pre-stress rates after rewatering is species-dependent, because only one of the tree species was able to fully recover. Furthermore, other research examined the effect of injecting $\mathrm{ABA}$ into the petioles of attached soybean (Glycine max) leaves and found that quantum yield and photosynthetic capacity were significantly reduced (Ward and Bunce, 1987). Conversely, Franks and Farquhar (2001) treated half of the Tradescantia virginiana plants in the study with $793 \mathrm{mg} \cdot \mathrm{L}^{-1}$ ABA solution for $13 \mathrm{~d}$ and reported that photosynthetic capacity was not significantly affected, although the ABA-treated plants had lower $g_{\mathrm{S}}$ and higher WUE. They concluded that studies in which photosynthesis appears to be diminished could be the result of patchy distribution of stomatal regulation by $\mathrm{ABA}$ and that many studies that have reported lower $\mathrm{P}_{\mathrm{n}}$ rates after ABA treatment were done in the short-term, whereas their experiment was conducted over the long-term (Franks and Farquhar, 2001). These conclusions are supported by Bradford et al. (1983), who found that long-term treatment with 2.6 and $7.9 \mathrm{mg} \cdot \mathrm{L}^{-1} \mathrm{ABA}$ solution applied as a spray had marginal effects on photosynthesis of tomato. Our findings indicate that ABA has a clear limiting effect on $g_{\mathrm{S}}$ and $\mathrm{P}_{\mathrm{n}}$, although future studies will be necessary to fully elucidate the role of ABA in limiting $P_{n}$ and specifically the role of stomatal versus non-stomatal factors, because findings are still controversial.

\section{Conclusions}

The use of ABA as a commercial means to extend the shelf life of retail plants shows promise. Leaf gas exchange measurements indicated that ABA drenches closed stomata and reduced transpiration within $1 \mathrm{~h}$ of the application. Daily ET of well-watered plants was reduced by ABA drenches for $5 \mathrm{~d}$, whereas ABA delayed wilting and extended the shelf life of unwatered plants by 2 to $8 \mathrm{~d}$, depending on the ABA concentration. This effect would be beneficial in extending the salability of retail plants. Negative side effects of the ABA drenches, chlorosis and leaf abscission, were noted and generally became more pronounced as ABA concentration increased. The lowest effective rate of ABA should be applied to extend shelf life without imposing side effects.

\section{Literature Cited}

Abrams, S.R., P.A. Rose, A.J. Cutler, J.J. Balsevich, B. Lei, and M.K. Walker-Simmons. 1997. 8'methylene abscisic acid: An effective and persistent analog of abscisic acid. Plant Physiol. 114:89-97.

Armitage, A.M. 1983. Keeping quality of bedding plants. Florists' Review 171:63-66.

Astacio, M.G. and M.W. van Iersel. 2012. Concentrated exogenous abscisic acid drenches reduce root hydraulic conductance and cause wilting in tomato. HortScience (in press).

Barrett, J.E. and C.A. Bartuska. 2011. s-ABA delays wilting in petunia and impatiens. Acta Hort. 893:1271-1276.

Barrett, J.E. and C.A. Campbell. 2006. (S)-ABA: Developing a new tool for the big grower. Big Grower 1:26-29.

Blanchard, M.G., L.A. Newton, E.S. Runkle, and D Woolard. 2007. Exogenous applications of abscisic acid improved the postharvest drought tolerance of several annual bedding plants. Acta Hort 755:127-132.

Boldt, J.L. 2008. Whole plant response of chrysanthemum to paclobutrazol, chlormequat chloride, and (s)-abscisic acid as a function of exposure time using a split-root system. MS thesis, Univ. of Florida, Gainesville, FL.

Bradford, K.J., T.D. Sharkey, and G.D. Farquhar. 1983. Gas exchange, stomatal behavior, and $\delta^{13} \mathrm{C}$ values of the flacca tomato mutant in relation to abscisic acid. Plant Physiol. 72:245-250.

Bravo, L.A., G.E. Zúñiga, M. Alberdi, and L.J. Corcueca. 1998. The role of ABA in freezing tolerance and cold acclimation in barley. Physiol. Plant. 103:17-23.

Christmann, A., E.W. Weiler, E. Steudle, and E. Grill. 2007. A hydraulic signal in root-to-shoot signalling of water shortage. Plant J. 52:167-174.

Davies, W.J., J.C. Metcalfe, U. Schurr, G. Taylor, and J. Zhang. 1987. Hormones as chemical signals involved in root to shoot communication of 
effects of changes in the soil environment, $p$. 201-216. In: Hoad, G.V., J.R. Lenton, M.B. Jackson, and R.K. Atkin (eds.). Hormone action in plant development. A critical appraisal. Butterworths, London, UK.

Davies, W.J., S. Wilkinson, and B. Loveys. 2002. Stomatal control by chemical signaling and the exploitation of this mechanism to increase water use efficiency in agriculture. New Phytol. 153: 449-460.

Farquhar, G.D. and T.D. Sharkey. 1982. Stomatal conductance and photosynthesis. Annu. Rev. Plant Physiol. 33:317-345.

Franks, P.J. and G.D. Farquhar. 2001. The effect of exogenous abscisic acid on stomatal development, stomatal mechanics, and leaf gas exchange in Tradescantia virginiana. J. Plant Physiol. 125: 935-942.

Hartung, W., A. Sauter, and E. Hose. 2002. Abscisic acid in the xylem: Where does it come from, where does it go? J. Expt. Bot. 366:27-32.

Jiang, F. and W. Hartung. 2008. Long-distance signaling of abscisic acid (ABA): The factors regulating the intensity of the ABA signal. J. Expt. Bot. 59:37-43.

Kim, J. 2011. Water relations of bedding plants: Water use, drought physiology, and gene expression. $\mathrm{PhD}$ diss., Univ. of Georgia, Athens, GA.

Kim, J. and M.W. van Iersel. 2011. ABA drenches induce stomatal closure and prolong shelf life of Salvia splendens. Sci. Hort. 127:420-423.

Liang, J., J. Zhang, and M.H. Wong. 1997. Can stomatal closure caused by xylem ABA explain the inhibition of leaf photosynthesis under soil drying? Photosynth. Res. 51:149-159.
Mahdieh, M. and A. Mostajeran. 2009. Abscisic acid regulates root hydraulic conductance via aquaporin expression modulation in Nicotiana tabacum. J. Plant Physiol. 166:1993-2003.

Milborrow, B.V. 1974. The chemistry and physiology of abscisic acid. Annu. Rev. Plant Physiol. 25:259-307.

O'Donoughue, A.E., C.A. Bartuska, and J.E. Barrett. 2011. s-ABA effects on evapotranspiration and leaf burn in Salvia farinacea. Acta Hort. (in press).

Ohkuma, K., J.L. Lyon, F.T. Addicott, and O.E. Smith. 1965. Abscisin II, an abscission accelerating substance from young cotton fruit. Science 142:1592-1593.

Petracek, P.D., D. Woolard, R. Menendez, and P. Warrior. 2005. Challenges for the commercial development of s-abscisic acid (ABA). Proc. Ann. Conf. Plant Growth Regulat. Soc. Amer. 7-9. 1 Aug. 2011.<http://65.213.202.115/ pgrsa/archive/ 2005_Proceedings/papers/003.pdfs.

Runkle, S.E. 2009. ABA coming to floriculture. Greenhouse Product News 19:42.

Sharma, N., D.R. Waterer, and S.R. Abrams. 2006. Evaluation of abscisic acid analogs as holding agents for bedding plant seedlings. HortTechnology 16:71-77.

Tallman, G. 2004. Are diurnal patterns of stomatal movement the result of alternating metabolism of endogenous guard cell ABA and accumulation of ABA delivered to the apoplast around guard cells by transpiration? J. Expt. Bot. 55: 1963-1976.

van Iersel, M.W., K. Seader, and S. Dove. 2009. Exogenous abscisic acid application effects on stomatal closure, water use, and shelf life of hydrangea (Hydrangea macrophylla). J. Environ. Hort. 27:234-238.

Walton, D.C. 1980. Biochemistry and physiology of abscisic acid. Annu. Rev. Plant Physiol. 31:453489.

Ward, D.A. and J.A. Bunce. 1987. Abscisic acid simultaneously decreases carboxylation efficiency and quantum yield in attached soybean leaves. J. Expt. Bot. 38:1182-1192.

Waterland, N.L., C.A. Campbell, J.J. Finer, and M.L. Jones. 2010a. Abscisic acid application enhances drought stress tolerance in bedding plants. HortScience 45:409-413.

Waterland, N.L., J.J. Finer, and M.L. Jones. $2010 \mathrm{~b}$. Benzyladenine and gibberellic acid application prevents abscisic acid-induced leaf chlorosis in pansy and viola. HortScience 45: 925-933.

Waterland, N.L., J.J. Finer, and M.L. Jones. 2010c. Abscisic acid applications decrease stomatal conductance and delay wilting in droughtstressed chrysanthemums. HortTechnology 20 : 896-901.

Wilen, R.W., L.V. Gustabolei, S.R. Abrams, and B.E. Ewan. 1994. Effects of abscisic acid (ABA) and ABA analogs on freezing tolerance, low-temperature growth, and flowering in rapeseed. J. Plant Growth Regul. 13:235-241.

Willmer, C. and M. Fricker. 1996. Stomata. Chapman and Hall, London, UK.

Zeevaart, J.D. and R.A. Creelman. 1988. Metabolism and physiology of abscisic acid. Annu. Rev. Plant Physiol. Plant Mol. Biol. 39:439473. 